\title{
Study on the Aesthetics of Han Chinese Clothing Culture in the TV Play "Nirvana in Fire"
}

\author{
Xiaofang Ma \\ Academy of Fine Arts \\ Yanbian University \\ Jilin, China
}

\begin{abstract}
This article takes "Nirvana in Fire" as the research object, analyzes the aesthetic appearance of Han Chinese clothing culture from the perspective of the Chinese clothing dress of the characters in the drama. Thousands of drama costumes have sophisticated modeling. The aesthetics is rigorous. It can be the example of Han Chinese clothing. Viewers could see the clothing etiquette, and understand the clothing characteristics in Southern and Northern Dynasties. It has achieved vivid aesthetic appearance of art.
\end{abstract}

Keywords-Nirvana in Fire; Han Chinese clothing culture; aesthetic appearance

\section{INTRODUCTION}

With the broadcast of the popular drama "Nirvana in Fire", the audience admires the content of the drama. And the fine production of the costume and props of the drama have attracted much attention. The drama refers to the dress regulation and aesthetic characteristics of the Wei, Jin and Southern and Northern Dynasties. Also, it refers to the ancient etiquette norms than other TV costume dramas. Thus, the drama shows the production of meticulous and high requirements in the costume. The selection of the clothing fabrics, the collocation of the colors, the embroidery shadows on the fabrics, the bun of the crown and cap on the head, and the jade on the waist have all been carefully designed and deliberated. We could compare the broadcast of "Nirvana in Fire" with the current costume dramas. And the costume matching details can be said to be ultimate. The audience would find everything fresh and new. In the whole drama "Nirvana in Fire", there are a total of thousands of suits of clothing. And the audience would be addicted to each piece of clothing. The costume is sophisticated and well-made. The aesthetics is rigorous. It can be called the masterpiece of Han Chinese clothing.

"Nirvana in Fire" is just a TV play. Its original work was alternate history. However, radio and television do not allow alternate history. And it was set in the Southern and Northern Dynasties. Fashion design is not completely reverted to the clothing of Liang dynasty. It is basically tells the stories of the Southern Liang dynasty in the Southern and Northern period. And the Southern and Northern dynasties mainly follow the Han system. The clothing and crown has inherited from the Han Dynasty. The clothing modeling greatly respected the background of the time. And the degree of reduction is very high. The apparel modeling was set in the Southern and Northern Dynasties. And it basically adopted the clothing regulation of Wei, Jin and Southern and Northern Dynasties. And it has reformed the clothing of front and rear dynasties. The loose dress became the fashionable clothing at that time. Men would wear long sleeves and elegant clothes. They would pursue comfortable, relaxed and casual feelings. The top-wear of women's costumes is simple. The underwear is plentiful. Normally, they would wear jacket and shirt. For the lower part of the body, they would wear skirt. The body part is closely fitted. The cuff is very big. And the lower body would have long skirt on the ground. It is multi-pleated loose skirt. And the layer is upon layer. It shows elegant style. The female hairstyle is mainly bun. They would have step shake jewelry on the bun. The rich jewelry would reflect the luxury. During this period, there were frequent wars among the nationalities, which resulted in the mutual influence and fusion of the national costumes.

\section{THE APPAREL MODELING OF "NIRVANA IN FIRE"}

Apparel modeling is an important part of role shaping in film and TV dramas. It gives the audience a visual aesthetic feeling. And it would play an irreplaceable role in the role performance of the story plot. And the grasp of the details would be meticulous.

All the characters have dressed correct right lapel. "Nirvana in Fire" avoids the low-grade mistakes often made in the past costume dramas. All the characters' costumes have correct right lapel. That is, the front part of a Chinese robe or jacket should cover the right part, which is an important symbol of the Han nationality. In ancient China, the front part of costumes of some ethnic minorities was generally on the left. It is different from those of the Central Plains. Therefore, the left lapel was also used to refer to the rule of the foreign nationalities. In addition, the left lapel was also used to refer to the deceased. Han tradition and the left lapel were used to dress the deceased. Therefore, the left lapel and the right lapel of the costumes were very important and could not be ignored.

A jade worn by the aristocrats was tied to a garment band and used as an ornament. Also, it is used to suppress the clothing. Wearing jade is a symbol of status. All people who are known as literati wear jade ornaments according to their status. They also wear jade according to their rank and 
occasion. There are jasper and jade. The hanging of the jade in front of the skirt is based on the principle of "male left and female right" ("Fig. 1"), which is extremely elegant and correctly worn in front of the body, rather than being placed on the side of the body in some ancient TV dramas.

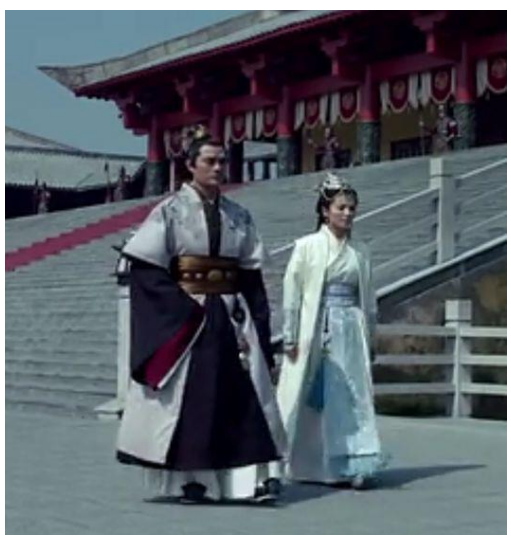

Fig. 1. The hanging of jade in front of skirt.

The dresses of the officials inside and outside the courtyard are not the same. The main figures would wear official uniforms, dresses and household casual clothing and other clothing in different occasions. The king of Jing, the princess of the Ni-Huang, Mengzhi commander and other military generals would wear armor uniform. Officials in a high position would have many suits of clothing to replace. It well interprets its status.

All adult men in "Nirvana in Fire" rigorously have hair knot. The adult men in ancient times all wanted to bundle their hair, which embodied the strict rules and etiquette.

\section{THE DRAMA COSTUMES OF "NIRVANA IN FIRE" FOLLOW THE HIERARCHICAL CHARACTERISTICS OF HAN CHINESE CLOTHING}

In the aspect of clothing fabric, they would select different clothing fabric such as the cotton and hemp material or the silk material according to character's class identity. Ancient clothing materials are strictly limited. To wear what clothes and material will have a clear system for each class. In "Nirvana in Fire", the imperial relatives, military officials, civilian officials, tramp, imperial secretary, and so on would wear different clothing fabric, clothing color, clothing patterns, and clothing kits according to the different status of the characters. The costume of the common people in the play is made of plain cotton and hemp cloth. People of grade and rank are all dressed in satin. There are jacquards, texture or embroidery on the clothes. It would not use light board cloth. For example, the royal nobility would use the dull or dark silk material. There are some patterns on it. The neckline and cuffs will be decorated with dark gold material. The king of Liang, Ni Huang princess and many princes would dress that design. Considering that the bright satin fabrics would reflect the light, no bright satin is used in the whole play.
In terms of dress color, the color of the characters' costume in Nirvana in Fire is generally simple and elegant. And the overall style is light. It strictly follows the hierarchical features of the Western Han dresses. The main color of the royal dress is red. The higher the position is, the darker thy would dress. And in the Southern and Northern Dynasties, they would take the black as the honor. The emperor and the queen can wear the pure black dress in the drama. There is a distinct distinction between the costumes of the king who has seven pearls and that of the king who who has five pearls. The costume of the king of $\mathrm{Yu}$ is red. And the king of Jing is dark gray or blue-white. And the textures of their clothes are different. The king of $\mathrm{Yu}$ is dressed in satin embroidered gold, while the king of Jing is only dressed in dark satin pattern, showing the distinction between inferiority and superiority everywhere. With the elevation of the status of the characters, the color of the clothes also changed. And the fabrics and colors has become more gorgeous and noble. For example, the role of the king of Jing changed from the Dukes to the Prince, and the color of the clothes also changed from the blue-gray, dark red to the red. And it changed with the improvement of position.

In the aspect of dress pattern, the noble class is different, and the embroidery pattern is also different. The patterns in the Southern and Northern Dynasties were based on the patterns of the Han dynasty. The characters in the drama were embroidered with various patterns, such as "Hui", "Flowing Cloud", "Geometrical", "Han Cornus", "Golden Line" and so on. The patterns embroidered on the emperor's clothes were dragon patterns. And the embroidered patterns on the clothes of the infanta and the imperial concubine were also carefully examined. There are common straw dragon patterns on royal costumes, (as shown in "Fig. 2"), and kui dragon patterns (as shown in "Fig. 3"). The royal clothes are embroidered with four-clawed pythons. For example, the clothes of king of $\mathrm{Mu}$ are embroidered with pythons. And the emperor's clothes are embroidered with the five-clawed golden dragons. These details are rigorous and accurate.

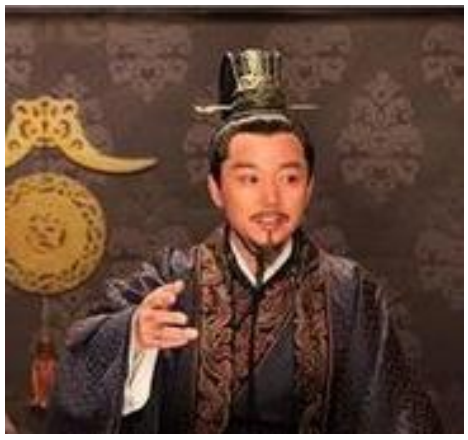

Fig. 2. Grass dragon pattern. 


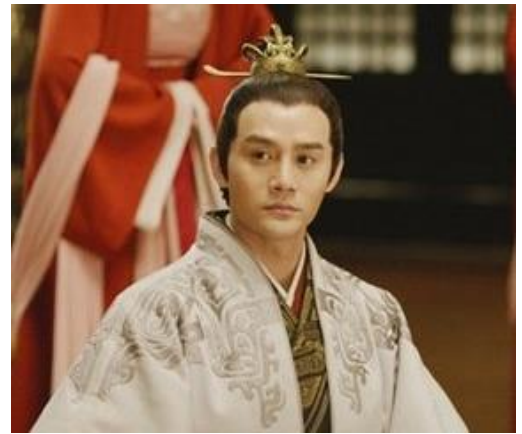

Fig. 3. Kui dragon pattern.

In the period of Wei, Jin, Southern and Northern Dynasties, according to different status, the royal nobility wear crown or caps. The normal people would wear "ze". The aristocrat's official cap could be divided into a variety of forms according to the hierarchy. From the material and modeling of male's crown and cap, we can distinguish their different grade and identity. For the different person, crown cap material would be different. There would have jade, bronze, sandalwood, gold and silver, silk and so on. The material is more precious, and the position is nobler. The king of Liang was the imperial throne. And he would wear a golden crown. And even, a golden hairpin would use cock decoration. The prince also wears a golden crown, which is very luxurious. In contrast, the king of Jing wears a bronze crown, the style of which is exquisite but not luxurious. And it shows that the situation of the king is not optimistic at that time. The crown system in the Wei and Jin Dynasties was inherited from the Han Dynasty. However, it was slightly different from that in the Han Dynasty. "Ze" was heightening. The size became smaller to the top. It was called "small crown". The "small crown" could be used in the field and countryside. Also, it is popular in north and south part of the nation. In the play, Mei Changsu has always worn a small crown made of white jade (as shown in "Fig. 4"). Mei Changsu's hair decoration is jade crown and jade hairpin. The scholar would wear white jade hair crown, which is closely related to the "jade culture" of China. The appearance of jade is exquisite and mild. However, the texture in it is hard and meticulous. In ancient Chinese culture, the jade represents warm, tolerance, nobility and faith. There is a saying that "men are warm and elegant". In the "Nirvana in Fire", Mei Changsu is at the top of the rank of talents. And he is a modest gentleman. He is warm, moral, and resolute, which are precisely Mei Changsu's personality characteristics. Li Gang, Zhen Ping and Tong Lu belonged to the Jiangzuo League. Li Gang and Zhen Ping were the former members of Chiyan Army. They have certain status. And Tong Lu was a civilian. Therefore, Li Gang and Zhen Ping wore a hair crown. Tong Lu wore a towel.

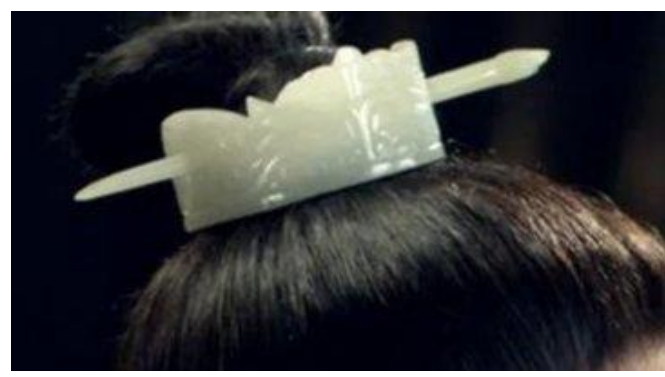

Fig. 4. A small crown made of white jade.

\section{ANALYSIS OF THE DRESS OF THE CHARACTERS IN THE DRAMA}

\section{A. Mei Changsu's Apparel Is Generally Simplistic}

Taking the hero Mei Changsu as an example, the audience could see that a man was in plain white with a flute in hand, catering to the character's low-key and introverted character. Mei Changsu is afraid of the cold. He is an introverted and calm person. The costumes are mostly plain white, blue and gray. As the first male protagonist, the costumes appear a little plain in appearance. They are in line with his talent and the status of a scholar. The fabric of the garment is made of cotton and hemp ("Fig. 5"). The texture is very good, and the skirt cuffs can be seen, which is in accordance with the status of the wandering people. It is in sharp contrast with the silk and satin of the royal and noble ministers in the palace. In details, Mei Changsu has always wore a white scarf around his neck, which is soft in texture. It highlights his weak, introverted and illness-prone image. The fur cloak used for keeping warm is also a major component of its clothing. In the last episode of the play, Mei Changsu took off his plain white linen clothes and put on the luxurious jacket that only senior generals could wear, symbolizing his return to the battlefield as Lin's descendants.

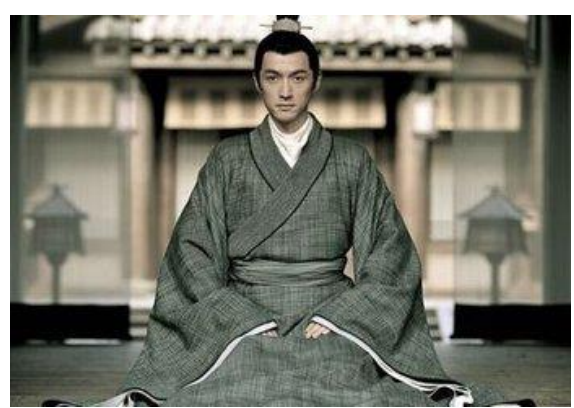

Fig. 5. Cotton and hemp clothing.

\section{B. Ni Huang Princess}

Liu Tao plays the role of Ni Huang princess of Yunnan, female general of south of Daliang. Compared with other female's wearing, Ni Huang's clothing style has masculine style. However, the sleeves would be softer. The color of the clothes is mainly white. It is simple and elegant, fresh and 
natural. The characters are dressed in plain clothes. The clothing fabric is made of satin. It is smooth in texture, and soft in color. (As shown in "Fig. 6") All of this would convey the noble identity of the princess without discernment. More praiseworthy is that the princess has been living in Yunnan for a long time. Most of the headgear is silver. It has all kinds of gemstones and jade beads with soft colors. And it has strong characteristics and exotic customs of Yunnan province. The cloak is made of fine texture fabric "brocade" ("Fig. 7"). With moonlight-like reflections, the fine pattern embroidered above is called "embroidery". And the cloak of the princess can be called "gorgeous cloak", revealing the dignity of temperament.

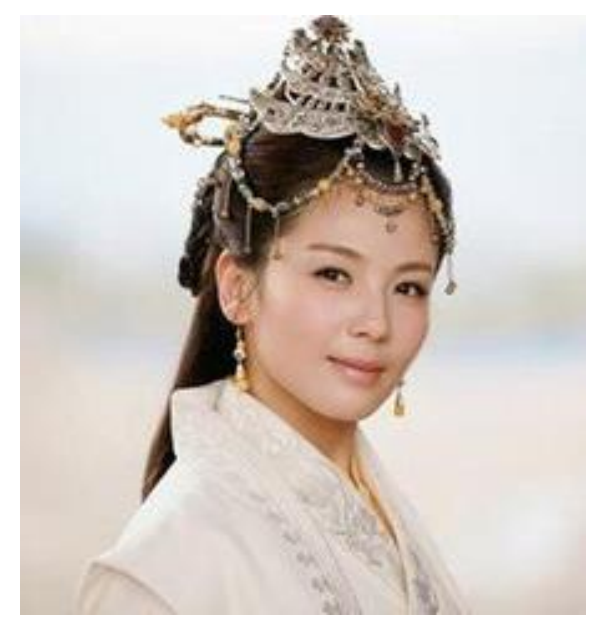

Fig. 6. The satin dress of Nihuang princess.

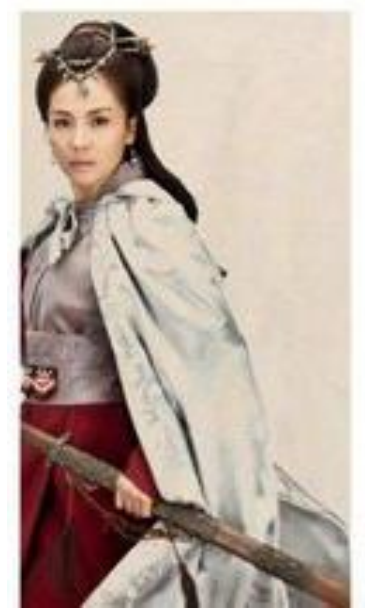

Fig. 7. The brocade cloak.

\section{The Dressing of the King of Jing in Different Occasions}

Official and casual dress design and production of the king of Jing is extremely elegant. When entering the palace, the king of Jing wore dark red official dress. It is embroidered with patterns, gold thread at the lapel cuffs. And he wore a pure gold cap ("Fig. 8"). In the daily, he would wear casual dress embroidered with a variety of fine texture of satin clothing. Also, he would wear a half-sleeved waistcoat-type jacket ("Fig. 9"). When he went outside, he would wear a woolly necktie cloak. And it is expensive ("Fig. 10"). He would wear armour uniforms ("Fig. 11").

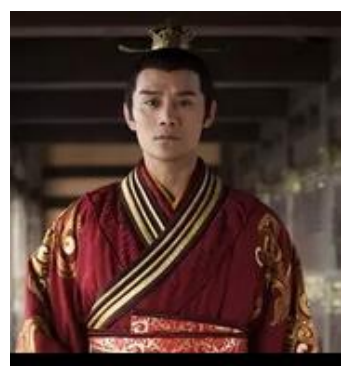

Fig. 8. Official uniforms of the king of Jing.

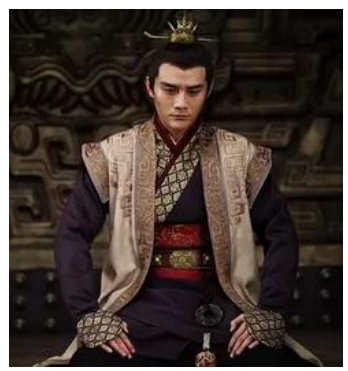

Fig. 9. Daily casual dress of the king of Jing.

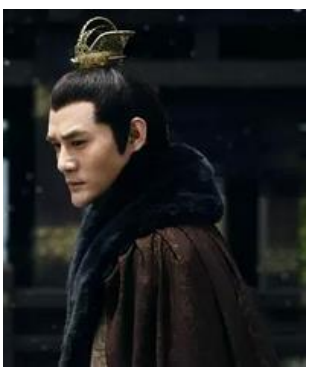

Fig. 10. The cloak of the king of Jing.

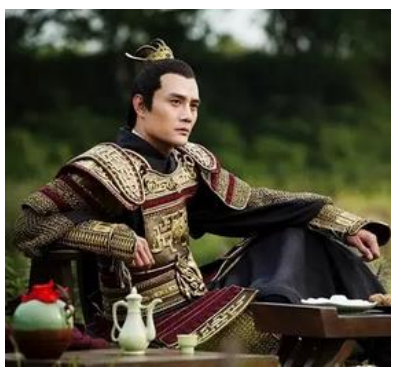

Fig. 11. Armor uniforms of the king of Jing.

\section{The Transformation Process of Imperial Concubine "Jing"}

Clothing modelling is related to the character plot. For example, the imperial concubine "Jing" had experienced the transformation from the low position to the noble concubine. And clothing design will also undergo a transformation from the elegance to nobility. When the position of the imperial concubine "Jing" is low, the color of clothes is light and 
simple. It is elegant fabric. It would use the embroidery dark lines on neckline cuffs to brighten the screen vivid ("Fig. 12 "). Hair decoration is exquisite but not luxurious. The head decoration is monochromatic simple hairpin. Sometimes they would use jade to decorate the hair bun, which would show elegant refined temperament of imperial concubine "Jing". With the development of the plot, imperial concubine "Jing" became a noble concubine. The costume of imperial concubine "Jing" began to use large areas of blue, orange and other colorful colors to highlight the dignity of her identity ("Fig. 13"). Head decoration also changes with the change of status. When the status is promoted to imperial concubine "Jing", the head wears golden crown. It is elegant and luxurious.

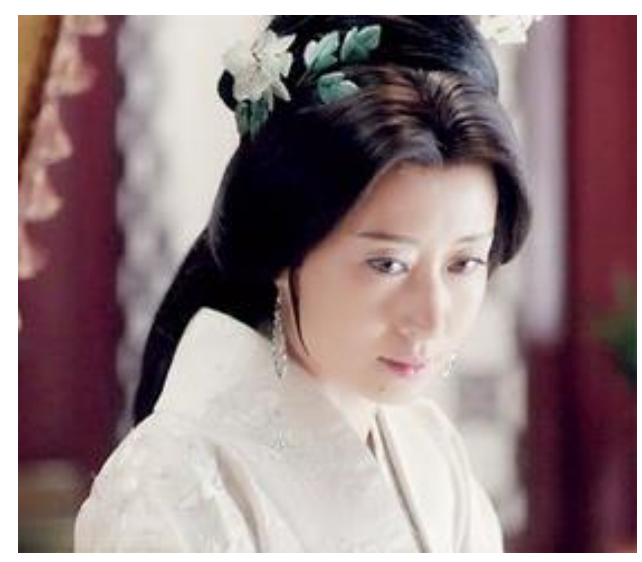

Fig. 12. Dress of elegant fabric of imperial concubine "Jing".

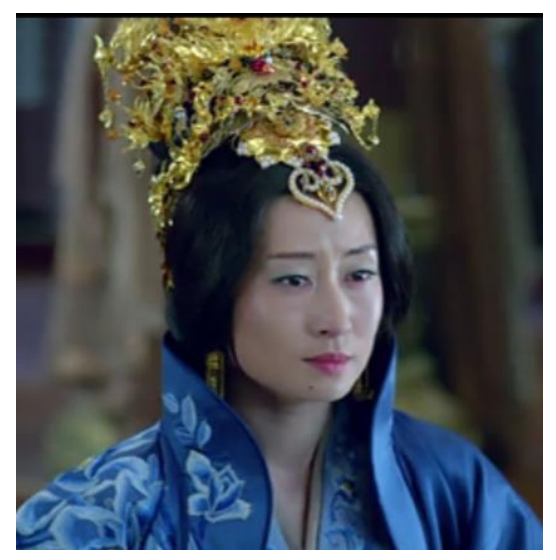

Fig. 13. Noble concubine costume of imperial concubine "Jing".

\section{E. Clothing of the Mass Actors}

The costumes of the actors in the drama are subtle and adaptable. All the details stand the scrutiny. And it would be exemplary in the work.

\section{CONCLUSION}

The "Nirvana in Fire" is alternate history novel. It strives for perfection in the details. And it returns to the common sense and essence of mass aesthetics. "Nirvana in Fire" opens up a new style of Chinese costume drama. And the core of revenge in the drama establishes the depressed tone of the drama. The overall style of the costume is relatively light and elegant. And all the details constitute a sense of texture. The audiences see the etiquette of the costume and understand the characteristics of the costume in the Southern and Northern Dynasties. From each modeling details, the audiences would have vivid artistic aesthetic presentation.

\section{REFERENCES}

[1] Fan Liping. The beauty of the etiquette and costumes in "Nirvana in Fire", Contemporary Television, 2017, 6. 《<琅哪榜〉的礼仪与服饰 之美》, 樊丽萍, 当代电视, 2017.6。

[2] Shi Weihua. Study on costume modeling in "Nirvana in Fire", Theater Home, 2015, 10 《小议电视剧《琅躯榜〉中的服装造 型》, 石伟华, 戏剧之家, 2015,10 